\title{
DEVELOPMENT OF A COMPUTATIONAL FLUID DYNAMICS SIMULATION TOOL FOR LUBRICATION STUDIES ON CYCLOIDAL GEAR SETS
}

\author{
F. CONCLI ${ }^{1}$, L. MACCIONI ${ }^{1} \&$ C. GORLA ${ }^{2}$ \\ ${ }^{1}$ Free University of Bolzano/Bozen, Faculty of Science and Technology, Bolzano, Italy. \\ ${ }^{2}$ Politecnico di Milano, Dipartimento di Meccanica, Milano, Italy.
}

\begin{abstract}
In the last decades, the growing mechatronic sector has promoted the development of more and more compact and efficient gearboxes. The margins of improvement are still big even if, sometimes, finding the optimal solutions is a trial and error procedure. For this reason, the development of dedicated tools for the optimization of the geometry and configuration of gearboxes can significantly increase the development effectiveness and help in reducing design costs. Moreover, having a more efficient solution could also reduce thermal problems during operation and increase the system reliability.

The so-called 'thermal limit', i.e. the maximum transmittable power without an overheating of the systems, is particularly critical for high power density and compact solutions. Those relies mainly on planetary, harmonic and cycloidal architectures. While many empirical or analytical prediction models can be found in literature for the prediction of the power losses associated with the gear meshing and the bearing, few reliable models are nowadays available for the losses associated with the interaction with the lubricant, i.e. hydraulic losses. Experimental and computational fluid dynamics studies on parallel axis as well as planetary gear sets have been presented in the past.

The goal of this research is the extension of the applicability range of those numerical approached to cycloidal kinematics for which no studies at all are available with respect to the hydraulic losses.

The main challenge in numerically simulate the lubricant splashing in a cycloidal reduced is related to the topological modification of the computational domain during operation. For this purpose, a specific mesh handling technique, based on a $2.5 \mathrm{D}$ mesh, capable to handle the variations of the geometry of the domain was developed in the OpenFOAM ${ }^{\circledR}$ environment. The capability to analytically control the mesh generation at each time step ensures a very high numerical stability and a very high computational efficiency of the solution.

Eventually, the approach was systematically applied to a real geometry and the results compared with those obtained for other gear architectures with comparable performances in terms of dimensions and reduction ratios.
\end{abstract}

Keywords: CFD, cycloidal gear, efficiency, lubrication, multiphase, power losses.

\section{INTRODUCTION}

In the current market, fierce companies offer a huge portfolio of high power density solutions. Each solution can show benefits and/or limitations depending on the specific application. The main parameters used in the selection of the proper solution are torque and speed (i.e. power), gear ratio (GR), backlash, external dimensions, efficiency, costs, etc.

The most widespread architectures used in mechatronic applications are the traditional planetary gears, the cycloidal architectures and harmonic drives. Cycloid and harmonic drives (considering having same number of stages) seem to be the best choice if the focus is GR. For GRs between 30 and 150, cycloidal architectures and harmonic drives show similar power densities [1]. However, the kinematic of the latter is not working for a GR below 30 . Moreover, harmonic solutions require very high tolerances in comparison with cycloidal and planetary gears [1], with a significant impact on the manufacturing costs. Consequently, for GRs in the range 10-30, only cycloidal and planetary gears can be an effective option. 
A cycloidal gearbox set is made by an input shaft on which an eccentric cam is milled, the cycloidal disk, an external annulus - usually directly manufactured in the housing - having a series of rollers engaging with the cycloidal disk and an output shaft in order to extract the power from the cycloidal disk. Practically this is often made by means of a hole-pin connection. The input shaft set the cycloidal disk into motion along a circular path thanks to the eccentric cam. The disk engages with the rollers of the annulus. Its rotating direction is opposite to the one of the input shafts. The cycloidal disk presents some holes that drag the pins of the output shaft, promoting the extraction of the power. This solution results unbalanced, and it is common practice to add additional counterweights or a second cycloidal disk (out of phase $180^{\circ}$ ).

The GR of a cycloidal architecture can be calculated as a function of the number of lobes of the cycloidal disk $Z_{1}$ and the number of rollers of the annulus $Z_{2}$.

$$
G R=\frac{\omega_{\text {input }}}{\omega_{\text {output }}}=\frac{Z_{1}}{Z_{2}-Z_{1}}
$$

The maximum GR is achieved when the difference in the number of rollers and lobes is $Z_{2}-Z_{1}$. This is the most widespread configuration.

Theoretically speaking, each roller engages with the corresponding lobe, but the transmitted force is not equally distributed among the contacts: only half of them, in fact, are really loaded [2]. Moreover, backlash between annulus and cycloidal lobes (required for a good lubrication and to ensure the assembly [3]) causes that the real load sharing is even different from the theoretical one. Sensinger et al. [1] presented the results of a $n$ numerical and experimental investigation of a cycloidal reducer with a single lobe-roll contact (worst loading condition). The maximum stress in the contact is purely a compressive one. Cycloidal architecture can therefore ensure a higher resistance to overloads (resisting to loads up to $500 \%$ of the nominal one). Moreover, in correspondence of the force maximum, the curvature of the profile has its maximum. This combination is exceptionally favourable from a loading capacity point of view.

The back side of the coin is that the efficiency of a cycloidal gear set is generally significantly below those of traditional planetary gears.

\section{POWER LOSS OF GEARS}

The power losses in gears are traditionally classified [4] into load dependent and load independent (sub-index $\left.\right|_{0}$ ). The latter are not directly affected by the transmitted torque (but only indirectly through the oil properties - function of the operating temperature), while the load-dependent ones are directly proportional to the torque. Losses can also be classified according to the component responsible for their generation

$$
P_{L}=P_{L G}+P_{L G 0}+P_{L B}+P_{L B 0}+P_{L S}+P_{L X}
$$

It is therefore possible to distinguish between gear- $\left.\right|_{G}$, bearing- $\left.\right|_{B}$, seal- $\left.\right|_{S}$ and generic-losses $\left.\right|_{X}$ (e.g. clutches or syntonizers).

In the past, several researchers have proposed empirical models for most of the sources of loss. The load-dependent losses of gears $\left(P_{L G}\right)$, for example, can be easily calculated for involute gears, with the ISO 6336 standard [5]. In these sense, various are the available examples of specific designs with increase the meshing efficiency [6-8].

Several studies have been carried out on the losses of bearing. The bearing manufacturer SKF, for example, proposed a detailed model [9]. Another very complete model was 
presented by Schaeffler [10]. It provides equations both for the prediction of all the loss contributions of bearings $\left(P_{L B}\right.$ and $\left.P_{L B 0}\right)$. The losses of seals $\left(P_{L S}\right)$ can be calculated with a rough model based on experimental evidences [4]. Only one source of loss that is not properly covered by accurate and with general validity models: the load-independent power loss of gears $\left(P_{L G 0}\right)$, i.e. the loss due to the interaction with the lubricant. Those can be further classified into windage, churning and squeezing/pocketing losses. The first one arises due to the interaction of the gears with a single fluid. Typically, this kind of losses are significant in high speed spray lubricated gears. The churning losses, on the contrary, involve two fluids, i.e. air and lubricant. Squeezing/pocketing losses are due to pressure gradients in the mating region related to the sudden volume change of the room between engaging teeth.

Many research groups worked on the development of experimentally based equations for the prediction of the load-independent power losses of gears $\left(P_{L G 0}\right)$. Daily and Nece [11] as well as Mann and Marston [12], for example, derived models for the description of churning of smooth discs. The models were improved by other researchers such as Ohlendorf [13] and extended to gears. This notwithstanding, the model was still applicable only to a single rotating gear. A significant step forward in the knowledge was done by Richter [14] whose model was the first to consider the mutual interaction of gears. Systematic research carried out by Terekhov [15] showed the influence of many parameters such as rotational velocity, gear size, immersion depth, tooth width, reduction ratio and lubricant properties on the squeezing and churning losses. The equations by Terekhov was successively modified by Walter $[16,17]$. Another milestone is the work of Mauz [18]. Recently, experimental investigations were carried out by Changenet and coworkers [19] and by Höhn et al. [20]. Nevertheless, all experimentally derived equations can be applied to spur gears only. Furthermore, their applicability is restricted to a short range of operating conditions. Limitations have been overcome thanks to numerical methods such as computational fluid dynamics (CFD). The first studies were performed by Diab et al. [19], Marchesse et al. [21] and, more recently, Gorla et al. [22-24]. The main drawback of the numerical approaches is the long computational time needed for the solution. Studies and tries performed in order to improve the computational performances are also available [25-26]. Smooth particle hydrodynamics based studies were shown by Groenenboom et al. [27], Ji et al. [28], Liu et al. [29], Rahmatjan and Geni [30], Shi et al. [31], Imin and Geni [32], Zhigang et al. [33] and Liu et al. [34]. A review paper showing advantages and drawbacks of the main available approaches was presented by Concli and Gorla [35].

This absence of reliable models for the load-independent power losses of gears is even more significant for cycloidal architectures [36]. In additions to the losses due to sliding in bearings (on the eccentric input shaft), between the rollers and cycloidal disk and in the holes-pins contacts, hydraulic losses play a fundamental role and represent a significant shear of the total losses.

Although the friction-related losses have been widely discussed and data are available, for the hydraulic losses of cycloidal gears, no records at all are present in the scientific literature. The aim of this article is therefore to introduce a general-purpose procedure that can be applied to any configuration. The results are reported to show the capabilities of the method and its effectiveness in studying the lubrication phenomenon also for complex kinematics.

\section{FINITE VOLUME APPROACH}

Several authors have already modelled the lubricant fluxes and power losses of planetary gears with finite volume approaches [37-44]. In this research, the Global Remeshing Approach (GRA) [45], previously developed by the author, was applied to a cycloidal gear set. 
The solver used handles two incompressible fluids, capturing the free surface through a volume of fluid approach. Mesh motion can be also handled. The solver is based on the solution conservation equations for mass and momentum

$$
\begin{gathered}
\frac{\partial \rho}{\partial t}+\nabla \cdot(\rho \boldsymbol{v})=0 \\
\frac{\partial(\rho \boldsymbol{v})}{\partial t}+\nabla \cdot(\rho \boldsymbol{v} \boldsymbol{v})=-\nabla p+\nabla \cdot\left[\mu\left(\nabla \boldsymbol{v}+\nabla \boldsymbol{v}^{T}\right)\right]+\rho \boldsymbol{g}+\boldsymbol{F}
\end{gathered}
$$

where $\rho, \boldsymbol{v}, \mu, \boldsymbol{g}$ and $\boldsymbol{F}$ represent density, velocities (vector), viscosity, gravitation and external forces, respectively.

A set of balance equations is written for each volume of the domain. The solving of the equations is done by means of a PIMPLE (merged PISO-SIMPLE) scheme, which merges the computational efficiency of the SIMPLE algorithm with time conservativeness of the PISO one.

The presence of more than one phase (air and lubricant) implies the need of an additional equation.

$$
\frac{\partial}{\partial t} \alpha+\frac{\partial}{\partial x_{i}}\left(\alpha u_{i}\right)=0
$$

$\alpha$ describes the amount of lubricant in each cell. It is a scalar that varies from 0 to 1 . Each property $(\varphi)$ of the mixture is, for each volume, calculated as the $\alpha$-averaged value of those of the lubricant and air.

$$
\phi=\phi_{l u b} \cdot a+\phi_{\text {air }} \cdot(1-\alpha)
$$

\section{MESH HANDLING}

CFD analysis of gears is intrinsically complex due to the variation of the topology of the computational domain during the calculation. Severe mesh distortions can take place and it is often needed to upgrade the mesh as simulation progresses. The authors have tested general purpose software that can handle automatically the grid update. The approach is effective, but its efficiency is low. There is a poor control of the element dimension and shape already from the first mesh update. Small cells are created to fill the holes where excessively distorted elements were automatically deleted. This can lead to an increment in the computational time needed for the solution, not so much for the increased number of cells, but for the need to limit drastically the time step (to keep the Courant number equal to 1) ensuring the numerical convergence. GRA was proved to be more efficient [46]. It allows a significantly better control of the shape of the updated mesh, ensuring a reduced computational effort due to the time steps that should not be reduced.

The domain is remeshed in toto after a certain number of time steps (Fig. 1). The fields ( $v$, $\rho, \alpha)$ of the last time step were copied on the new grid.

OpenFOAM ${ }^{\circledR}$ has two meshing algorithms implemented. The simplest one, blockMesh, creates regular hexahedral or wedge grids. Unfortunately, it is not effective for systems with a high geometrical complexity. On the other side, snappyHexMesh generates threedimensional (3D) meshes starting from stereolithography files. The mesh conforms to the geometry by iteratively refining a starting structured grid obtained for example with blockMesh and morphing the resulting split-hex mesh to the surface. This scheme is very stable and produces high-quality grids. However, it is not performing and, therefore, not suitable for the purposes generating subsequent grids. 

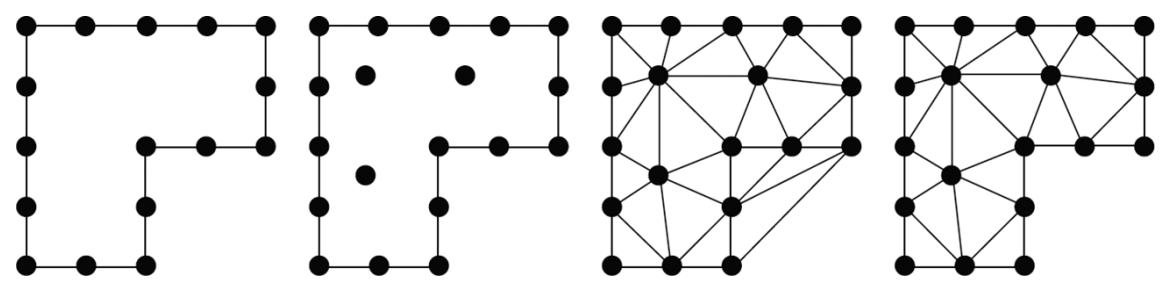

Figure 1: Mesh generation steps - Delaunay algorithm [46].

In this study, the two-dimensional (2D) mesh was generated using a top-down strategy.

If the mesh generation fails and the last elements cannot be created, a back-tracking rule based algorithm takes over [39][48]. The Delaunay algorithm discretizes the edges into segments with a prescribed seed size. Similarly, also the faces are seeded. The points are then connected during triangulation. If the results of the triangulation exceed the boundaries, the protruded elements are removed.

Figure 2 shows the flow chart of the GRA [49]. An initial grid is computed, and the solution of the conservation equations performed up to the point in which the quality of the mesh becomes unacceptable. A new mesh is generated on the topology of the domain of the previous time step. The results are copied from the old to the new grid and the simulation restarts. The procedure is repeated up to the end of the simulation.

Figure 3 shows an example of mesh degradation and successive mesh update.

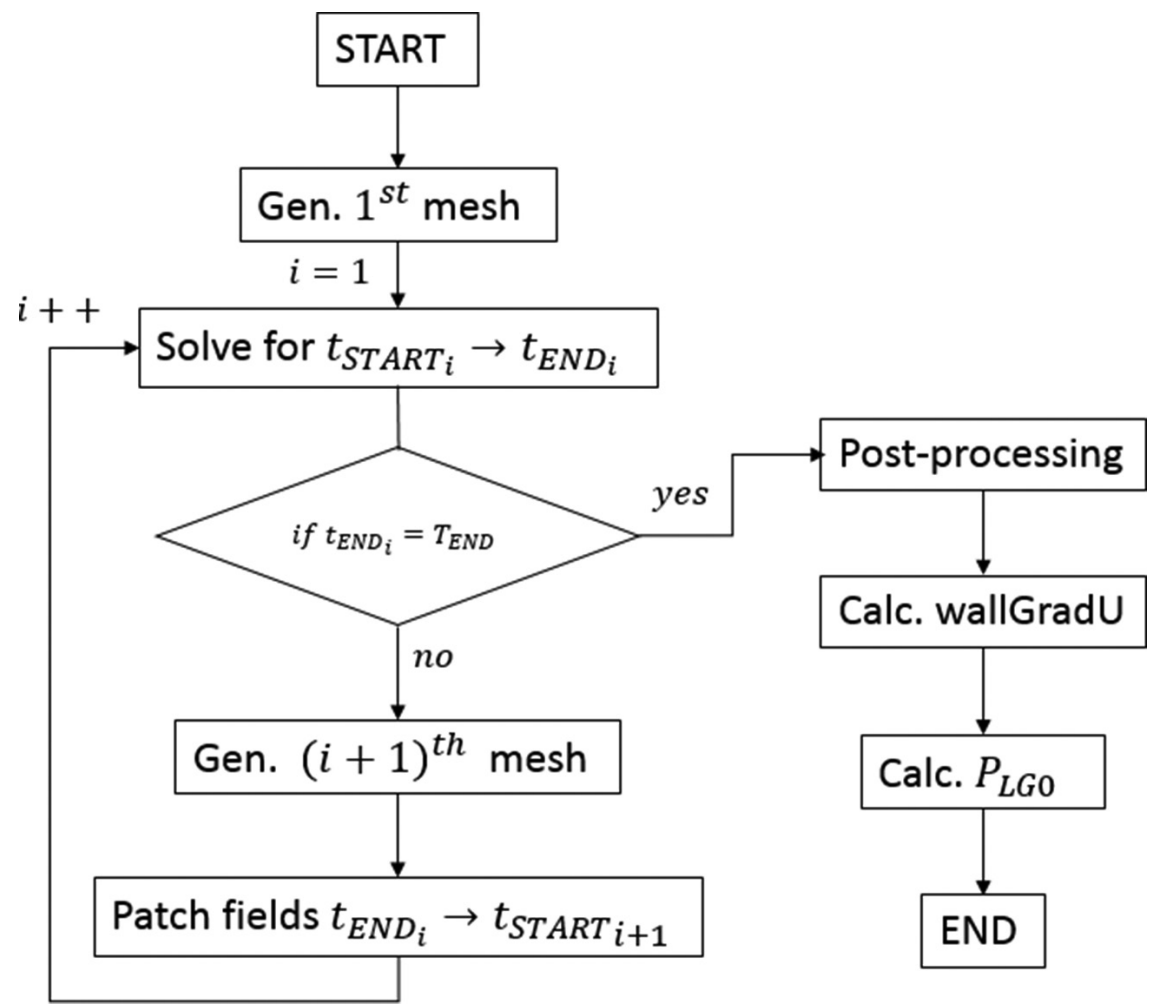

Figure 2: Global Remeshing Approach algorithm. 


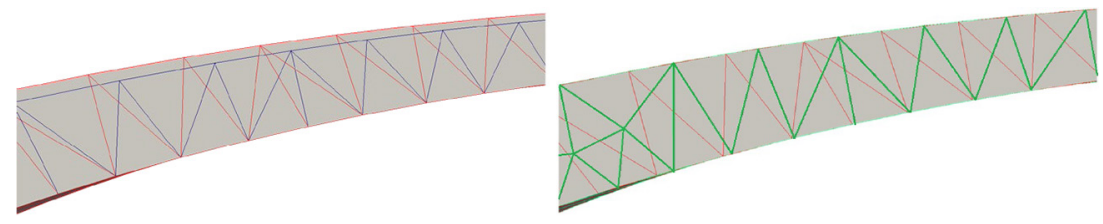

Figure 3: Example of mesh update; left: grid before the deformation (blue) and after several time steps (red); right: deformed mesh of the previous time step (red) and new mesh (green).

\section{CYCLOIDAL GEAR SET}

The shape of a cycloidal can be described by the Cartesian coordinates $C_{x}$ and $C_{y}$ as function of a parameter $\varphi$ called 'angle of input shaft' $(0$ and $2 \varpi)$.

$$
\begin{array}{r}
C_{x}=\mathrm{R} \cdot \cos (\phi)-R_{r} \cdot \cos (\phi+\psi)-\mathrm{e} \cdot \cos \left(\left(Z_{1}+1\right) \cdot \phi\right) \\
C_{y}=-\mathrm{R} \cdot \sin (\phi)+R_{r} \cdot \sin (\phi+\psi)+\mathrm{e} \cdot \sin \left(\left(Z_{1}+1\right) \cdot \phi\right) \\
\quad \text { where } \psi=\tan ^{-1}\left(\frac{\sin \left(Z_{1} \cdot \phi\right)}{\cos \left(Z_{1} \cdot \phi\right)-\frac{\mathrm{R}}{\mathrm{e} \cdot\left(Z_{1}+1\right)}}\right)
\end{array}
$$

$R$ is the distance between the centre of each roller and the axis of the input shaft. $R_{r}$ is the rollers radius, $e$ is the eccentricity of the input shaft and $Z_{1}$ is the number of lobes of the cycloid [50].

Considering that the goal of this study was to compare the load-independent losses of a traditional planetary gear set [37] with a comparable cycloidal gear set, the configuration of the latter was selected to have the same GR and comparable dimensions and transmittable torque.

$$
R=40 \mathrm{~mm} ; R_{r}=5 \mathrm{~mm} ; e=2 \mathrm{~mm} ; Z_{1}=10
$$

The radial backlash of $0.1 \mathrm{~mm}$ was selected. The pin-hole connection as well as additional balancing cycloids were neglected.

\section{RESULTS AND DISCUSSION}

In a first stage, 2D CFD analysis was performed. The lateral gaps (between internal shaft and external housing) were not modelled. This assumption is acceptable if the width in the axial direction is considerable. The engagement between the two cycloids (internal and external ones) produces squeezing effects [51-53]. This phenomenon is shown in Figs. 4-6. The gap between the lobes decreases suddenly and an overpressure generates (Fig. 7). The oil is squeezed out. The opening of the vane (separation of the flanks of the internal and the external cycloids) promotes a pressure reduction. Vortices can take place. The fluxes are mainly in the region filled with air while the lubricant seems to have less turbulent behaviour.

The pressure is uniform in each vane.

Additional simulations were performed on a planetary architecture with the same reduction ratio. The 2D simulations of the planetary gearbox show squeezing effects similarly to the cycloidal gear set. However, in this configuration, the squeezing phenomenon was limited to the proximity of the engagement (Fig. 8). The bigger interspaces of planetary 


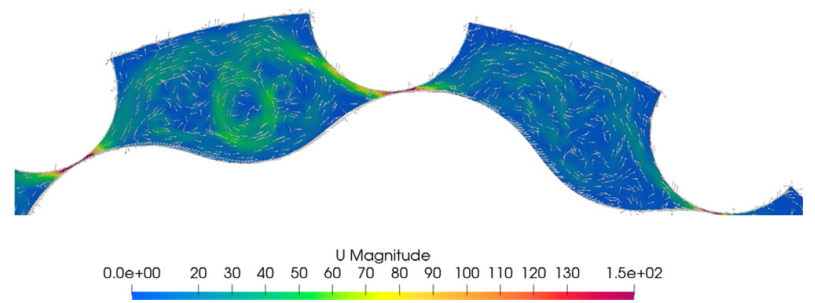

Figure 4: Contour plot: velocity and oil distribution $(U[\mathrm{~m} / \mathrm{s}])$.

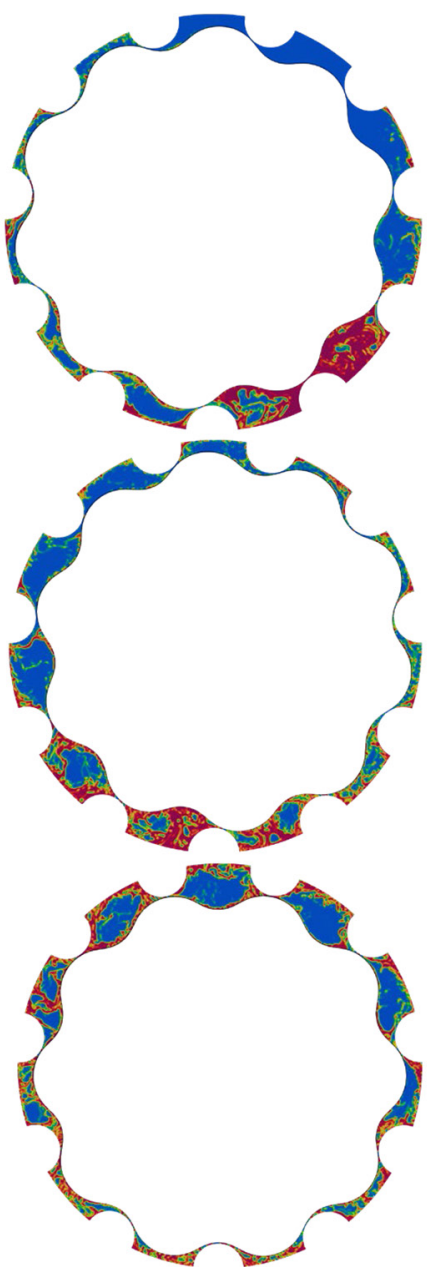

alpha.oil
$0.0 e+00 \quad 0.20 .30 .40 .50 .60 .70 .8 \quad 1.0 e+00$

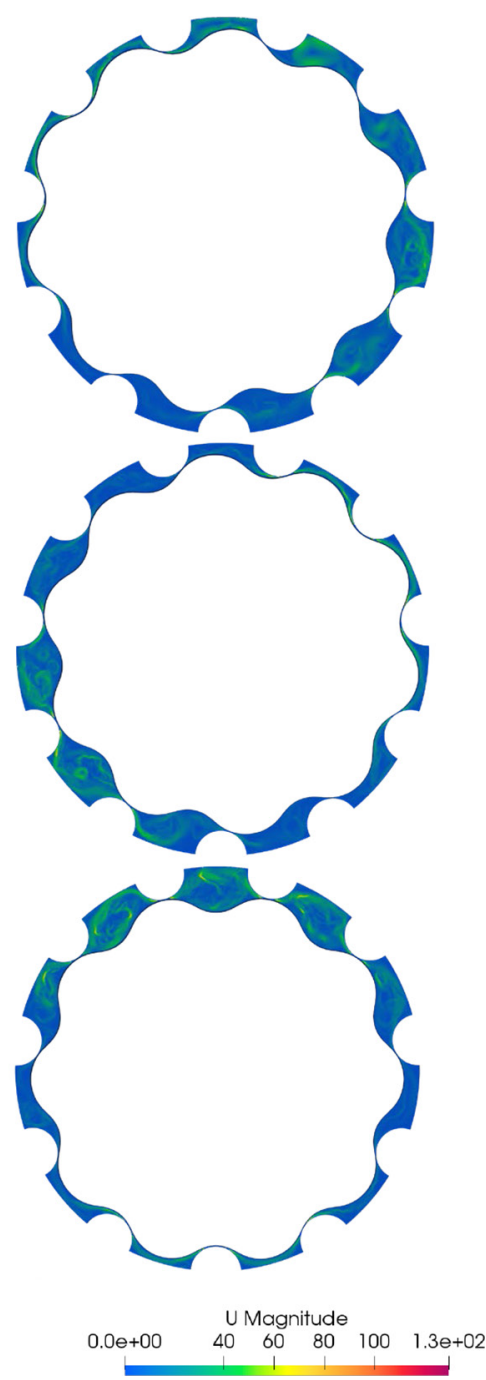

Figure 5: Details of the circulation effects: on the right, a gap that is closing, and on the left, a gap that is opening. The squeezing effect can be clearly observed (alpha.oil [-], $\mathrm{U}[\mathrm{m} / \mathrm{s}])$. 

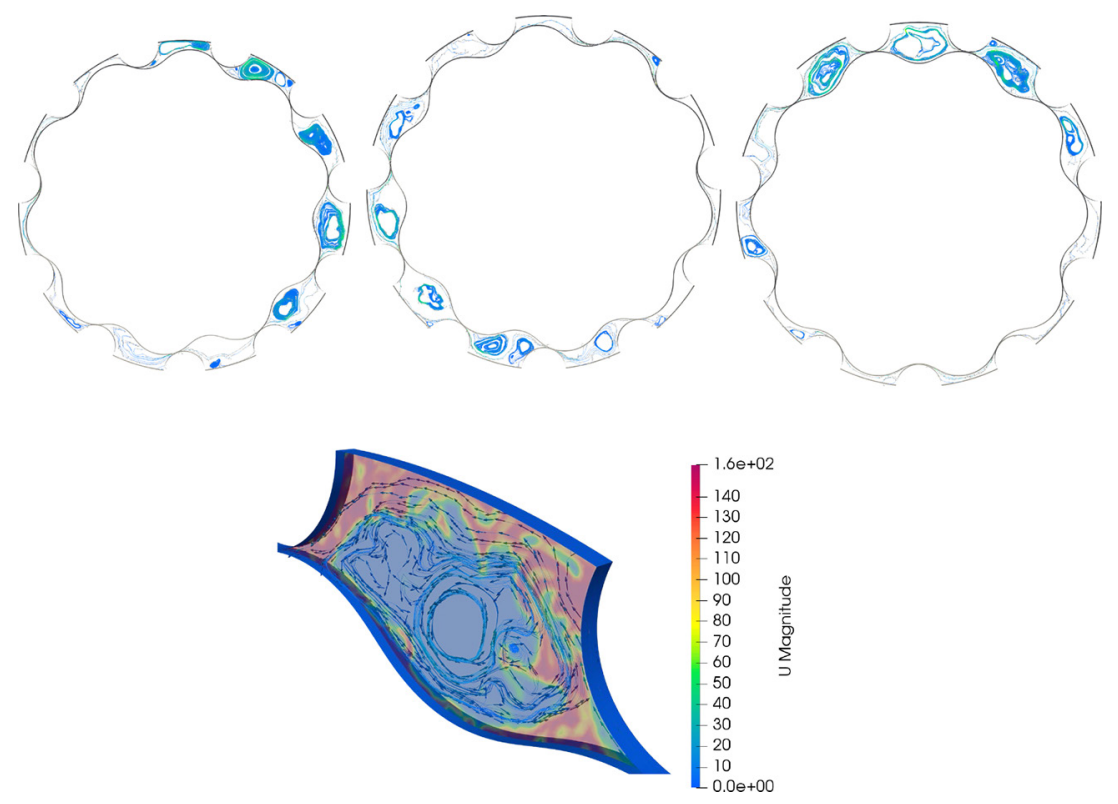

Figure 6: Streamlines and oil volume fraction contour $(U[\mathrm{~m} / \mathrm{s}])$.

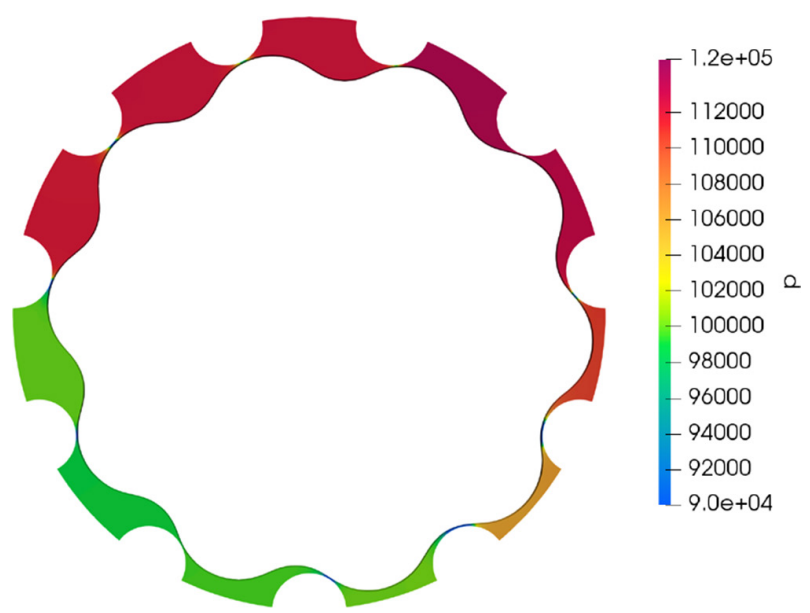

Figure 7: Pressure distribution in the different gaps (p $[\mathrm{Pa}])$.

configurations encourage a more widespread circulation of the lubricant limiting significantly the squeezing. On the other hand, the planetary configuration shows much higher churning and splashing of the oil. This is related to the translation of the planets that promotes the acceleration of big amount of oil.

Eventually, the two abovementioned architectures were simulated also in 3D. The aim of this preliminary study is to show the capabilities of the method rather than studying these two specific configurations. Nevertheless, some comments could be made observing Fig. 9.

The 3D approach allows to model also the lateral gap between planet carrier and housing in the planetary configuration and between the cycloidal disk and the housing for the 

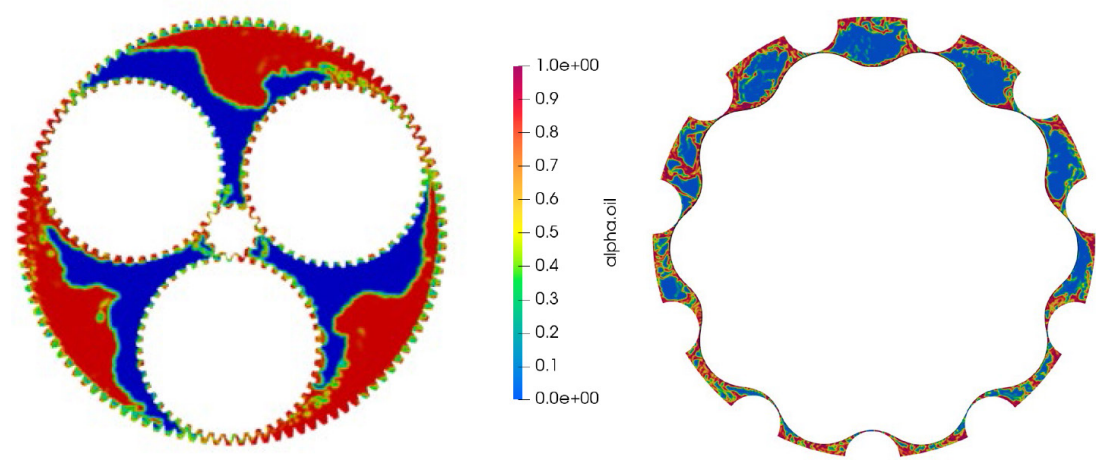

Figure 8: Traditional planetary gear set [7] vs. cycloidal configuration (reduction ratio 10) (alpha.oil [-]).
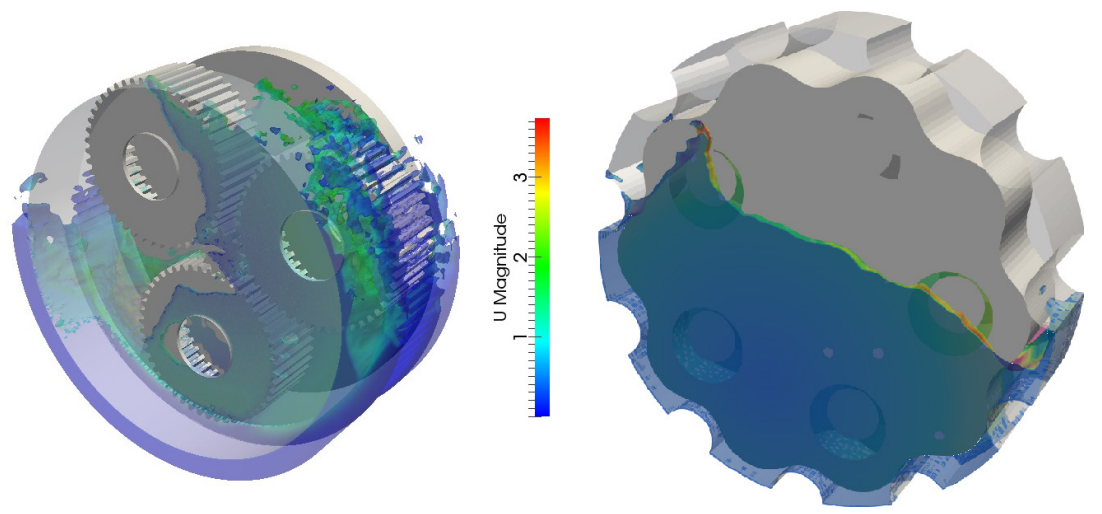

Figure 9: Traditional planetary gear set [7] vs. cycloidal configuration (reduction ratio 10) $(\mathrm{U}[\mathrm{m} / \mathrm{s}])$.

cycloidal gear set. In both cases, Couette flows are visible. This phenomenon was already observed for spur gears by several authors [54-57] confirming once again the high potential of this method.

From the $3 \mathrm{D}$ results, it could be noticed that the $2 \mathrm{D}$ assumption is acceptable for the planetary configuration where the axial width is of a higher order of magnitude with respect to the teeth high. On the other hand, for the considered 3D cycloidal configuration (selected in order to have the same load carrying capacity of the planetary gearbox), a 2D assumption is probably not the best choice. The axial width, in fact, is comparable to the lobe's high, and therefore, axial flows could not be neglected.

This consideration is also supported by the computational effort required for the cycloidal kinematic, and the 2D analysis was performed on a single CPU 9.6GFLOP workstation and took about 3 days to perform a complete rotation of the internal cycloid [36]. The corresponding 3D simulation (which number of cells is approximately 10 times higher) took about the same time. This is because the squeezing effects that took place in the $2 \mathrm{D}$ model are not present in the $3 \mathrm{D}$ one. In latter, the velocities of the fluid are significantly reduced. Keeping the Courant number equal to 1 in both models implies to have significantly different time steps. One of the 3D models took longer but is significantly less than those of the 2D model. 
The 2D model of the planetary gearbox, on the same hardware (9.6GFLOP), would took about 1 day to reach the regime. The corresponding 3D model (30 times more cells) would took about 30 days (in reality the simulation was performed on a 211 GFLOP cluster and took $30 \mathrm{~h}$ ). This linear scalability between the $2 \mathrm{D}$ and the $3 \mathrm{D}$ model supports the assumption that the present configuration could be studied with a planar approach because squeezing effects are negligible.

The possibility of using the $2 \mathrm{D}$ approximation is therefore strongly dependent from the architecture of the system.

\section{CONCLUSIONS}

This article shows the results of a preliminary study concerning the lubrication of a cycloidal gear set performed on a 2D and a 3D model. Results were compared with those of a planetary architecture. The 2D simplification implies the neglection of the axial flows. This can be acceptable only for gearboxes whose axial width is much higher than the diameter. This is significantly dependent from the system architecture.

The adopted GRA strategy for the mesh deformation handling allowed to perform simulation of a complex kinematic in a reasonable amount of time. The simulations result very stable with a good numerical convergence. Moreover, it has been proved that this method can be successfully applied also to 3D models. Therefore, in the future, the approach will be systematically applied for dedicated studies of the lubrication of cycloidal gear sets.

The 2D analysis showed that the load-independent power losses of planetary gear sets are mainly related to churning (of the planet carrier and planets), while in cycloidal architectures, significant pumping/squeezing effects arise in the gaps near the meshing region due to variations of the volumes and the related pressure gradients. Vortices are present, especially in the opening gaps (where the lubricant/air mixture is squeezed from the previous gap that is reducing its volume). The vortices involve mainly the air while the lubricant flux seems to be laminar $(\operatorname{Re}<2 \mathrm{E} 3)$.

\section{REFERENCES}

[1] Sensinger, J. W. \& Lipsey, J. H., Cycloid vs. harmonic drives for use in high ratio, single stage robotic transmissions. 2012 IEEE Int. Conf. Robot. Autom., pp. 4130-4135, 2012.

[2] Gorla, C., Davoli, P., Rosa, F., Longoni, C., Chiozzi, F. \& Samarani, A., Theoretical and experimental analysis of a cycloidal speed reducer. J. Mech. Des. Trans. ASME, 130(11), pp. 1126041-1126048, 2008. https://doi.org/10.1115/1.2978342

[3] Blagojevic, M., Marjanovic, N., Djordjevic, Z., Stojanovic, B., Marjanovic, V., Vujanac, R. \& Disic, A., Numerical and experimental analysis of the cycloid disc stress state. Tech. Gaz., . 21(2), pp. 337-382, 2014.

[4] H. B. -r. Niemann, G., Winter, H, Maschinenelemente. 2005.

[5] ISO, “6336." 2006.

[6] Xia, Y., A new topology of CMG for high torque and low loss, 2016 Prog. Electromagn. Res. Symp. PIERS 2016 - Proc., 65(11-12), pp. 78-82, 2016.

[7] Concli, F., Low-loss gears precision planetary gearboxes: reduction of the load dependent power losses and efficiency estimation through a hybrid analytical-numerical optimization tool. Forsch. im Ingenieurwesen/Engineering Res., 2017.

[8] Anderson, N. E. \& Loewenthal, S. H., Design of spur gears for improved efficiency. J. Mech. Des. Trans. ASME, 104(4), pp. 767-774, 1982.

[9] "www.SKF.com.". 
[10] “www.schaeffler.it.".

[11] Daily, J. W. \& Nece, R. E., Chamber dimension effects on induced flow and frictional resistance of enclosed rotating disks. J. Fluids Eng. Trans. ASME, 82(1), pp. 217-230, 1960. https://doi.org/10.1115/1.3662532

[12] Mann, R. W. \& Marston, C. H., Friction drag on bladed disks in housings as a function of reynolds number, axial and radial clearance, and blade aspect ratio and solidity. $J$. Fluids Eng. Trans. ASME, 83(4), pp. 719-723, 1961. https://doi.org/10.1115/1.3662308

[13] Ohlendorf, H., Verlustleistung und Erwärmung von Stirnrädern. Verlustleistung und Erwärmung von Stirnrädern, 1958.

[14] Richter, W., Stirnradgetriebe, Zahnreibung, Verlustleistung und Erwärmung, 1964.

[15] Terekhov, A. S., Hydraulic Losses In Gearboxes With Oil Immersion. Russ Eng J, 55(5), pp. 7-11, 1975.

[16] Walter, P. \& Langenbeck, K., Anwendungegrenzen für die Tauchschmierung von Zahnradgetrieben, Plansch- und Quetschverluste bei Tauchschmierung, 1982.

[17] Walter, P., Untersuchung Zur Tauchschmierung Von Stirnrädern Bei Umfangsgeschwindigkeiten Bis 60 M/S, 1982.

[18] Mauz, W., Hydraulische Verluste von Strinradgetrieben bei Umfansgsgeschwindigkeiten bis 60 m/s, Hydraul. Verluste von Stirnradgetrieben Bei Umfangsgeschwindigkeiten Bis $60 \mathrm{M} / \mathrm{s}, 1987$.

[19] Diab,Y., Ville, F., Velex, P. \& Changenet, C., Windage losses in high speed gears-preliminary experimental and theoretical results. J. Mech. Des. Trans. ASME, 126(5), pp. 903-908, 2004. https://doi.org/10.1115/1.1767815

[20] Höhn, B. R., Michaelis, K. \& Otto, H. P., Influence on no-load gear losses. Ecotrib 2011 Conf. Proc., 2, pp. 639-644, 2011.

[21] Marchesse, Y., Changenet, C., Ville, F. \& Velex, P., Investigations on CFD simulations for predicting windage power losses in spur gears. J. Mech. Des. Trans. ASME, 133(2), 2011. https://doi.org/10.1115/1.4003357

[22] Gorla, C., Concli, F., Stahl, K., Höhn, B. R., Michaelis, K., Schultheiß, H., \& Stemplinger, J. P., Hydraulic losses of a gearbox: CFD analysis and experiments. Tribology International, 66, pp. 337-344, 2013. https://doi.org/10.1016/j.triboint.2013.06.005

[23] Stahl, K., Höhn, B. R., Michaelis, K., Schultheiß, H., Stemplinger, J. P., Gorla, C., \& Concli, F, CFD Simulations of Splash Losses of a Gearbox. Advances in Trobology, 10, 2012. https://doi.org/10.1155/2012/616923

[24] Concli, F., Gorla, C., Stahl, K., Höhn, B. R., Michaelis, K., Schultheiß, H., \& Stemplinger, J. P., Load independent power losses of ordinary gears: Numerical and experimental analysis. In 5th World Tribology Congress WTC 2013, 2, pp. 1243-1246, 2013. https://doi.org/10.1016/j.triboint.2013.06.005

[25] Concli, F., Gorla, C., Della Torre, A. \& Montenegro, G., Windage power losses of ordinary gears: Different CFD approaches aimed to the reduction of the computational effort. Lubricants, 2(4), pp. 162-176, 2014. https://doi.org/10.3390/lubricants2040162

[26] Concli, F., Gorla, C., Della Torre, A. \& Montenegro, G., Churning power losses of ordinary gears: A new approach based on the internal fluid dynamics simulations. Lubr. Sci., 27(5), 2015. https://doi.org/10.1002/ls.1280

[27] Groenenboom, P. H. L., Mettichi, M. Z. \& Gargouri, Y., Simulating Oil Flow for Gearbox Lubrication using Smoothed Particle Hydrodynamics. Proc. Int. Conf. Gears 2015, 2015. 
[28] Ji, Z., Stanic, M., Hartono, E. A. \& Chernoray, V., Numerical simulations of oil flow inside a gearbox by Smoothed Particle Hydrodynamics (SPH) method, Tribol. Int., 127, pp. 47-58, 2018. https://doi.org/10.1016/j.triboint.2018.05.034

[29] Liu, Z., Shen, Y. \& Rinderknecht, S., Theoretical and experimental investigation on power loss of vehicle transmission synchronizers with spray lubrication. SAE Tech. Pap., 2019, pp. 215-226, 2019.

[30] Rahmatjan I., \& Geni, M., SPH algorithm for proper meshing and coupling contact of gears. Zhendong yu Chongji/Journal Vib. Shock, 34(12), pp. 65-69, 2015.

[31] Shi, Y., Li, S., Chen, H., He, M. \& Shao, S., Improved SPH simulation of spilled oil contained by flexible floating boom under wave-current coupling condition. J. Fluids Struct., 76, pp. 272-300, 2018. https://doi.org/10.1016/j.jfluidstructs.2017.09.014

[32] Imin, R. \& Geni, M., Stress analysis of gear meshing impact based on SPH method, Math. Probl. Eng., 2014, 2014. https://doi.org/10.1155/2014/328216

[33] Zhigang, Y., Imin, R. \& Geni, M., Study on the gear modeling in SPH analysis. Adv. Mater. Res., 33-37, pp. 773-778, 2008. https://doi.org/10.4028/www.scientific.net/ amr.33-37.773

[34] Liu, H., Arfaoui, G., Stanic, M., Montigny, L., Jurkschat, T., Lohner, T., \& Stahl, K., Numerical modelling of oil distribution and churning gear power losses of gearboxes by smoothed particle hydrodynamics. Proceedings of the Institution of Mechanical Engineers, Part J: Journal of Engineering Tribology, 233(1), pp. 74-86, 2019.

[35] Concli, F. \& Gorla, C., Windage, churning and pocketing power losses of gears: different modeling approaches for different goals [Wirkungsgrad und Verluste von Zahnradgetrieben: Verschiedene Methoden für verschiedene Anwendungen]. Forsch. im Ingenieurwesen/Engineering Res., 80(3-4), pp. 85-99, 2016. https://doi.org/10.1007/ s10010-016-0206-9

[36] Concli, F., Maccioni, L. \& Gorla, C., Lubrication Of Gearboxes: CFD Analysis Of A Cycloidal Gear Set. In WIT Transactions on Engineering Sciences, 123, pp. 101-112, 2019.

[37] Concli, F. \& Gorla, C., Numerical modeling of the churning power losses in planetary gearboxes: An innovative partitioning-based meshing methodology for the application of a computational effort reduction strategy to complex gearbox configurations. Lubrication Science, 29(7), pp. 455-474, 2017. https://doi.org/10.1002/ls.1380

[38] Concli, F. \& Gorla, C., CFD simulation of power losses and lubricant flows in gearboxes. American Gear Manufacturers Association Fall Technical Meeting, 2017, 2017.

[39] Concli, F., Conrado, E. \& Gorla, C., Analysis of power losses in an industrial planetary speed reducer: Measurements and computational fluid dynamics calculations. Proc. Inst. Mech. Eng. Part J J. Eng. Tribol., 228(1), 2014. https://doi. org/10.1177/1350650113496980

[40] Concli, F., Thermal and efficiency characterization of a low-backlash planetary gearbox: An integrated numerical-analytical prediction model and its experimental validation. Proc. Inst. Mech. Eng. Part J J. Eng. Tribol., 230(8), 2016. https://doi. org/10.1177/1350650115622363

[41] Drewniak, J., Kopec, J. Zawislak, S., Kinematical and efficiency analysis of planetary gear trains by means of various graph-based approaches. Mech. Mach. Sci., 34, pp. 263-284, 2016. 
[42] Yin, H. B., Li, S. L., Zhang, H., Zhao, X. Y. \& Zhang, J., The power loss and efficiency analysis of a 3DOFs planetary gear box. Adv. Mater. Res., 834-836, pp. 1285-1289, 2013. https://doi.org/10.4028/www.scientific.net/amr.834-836.1285

[43] Concli, F \& Gorla, C., Computational and experimental analysis of the churning power losses in an industrial planetary speed reducer. WIT Transactions on Engineering Sciences, 74, pp. 287-298, 2012.

[44] Concli, F., \& Gorla, C., Influence of lubricant temperature, lubricant level and rotational speed on the churning power loss in an industrial planetary speed reducer: computational and experimental study. Int. J. Comput. Methods Exp. Meas., 1(4), pp. 353-366, 2013. https://doi.org/10.2495/cmem-v1-n4-353-366

[45] Concli, F. \& Gorla, C., Numerical modeling of the power losses in geared transmissions: Windage, churning and cavitation simulations with a new integrated approach that drastically reduces the computational effort. Tribol. Int., 103, pp. 58-68, 2016. https://doi.org/10.1016/j.triboint.2016.06.046

[46] Concli, F., Della Torre, A., Gorla, C. \& Montenegro, G., A new integrated approach for the prediction of the load independent power losses of gears: development of a meshhandling algorithm to reduce the CFD simulation time. Adv. Tribol., 2016, 2016.

[47] "www.hpfem.jku.at/netgen/.".

[48] Schöberl, J., An advancing front 2D/3D-mesh generator based on abstract rules. Comput. Vis. Sci., 1(1), pp. 41-52, 1997. https://doi.org/10.1007/s007910050004

[49] Concli, F., Gorla, C., Rosa, F. \& Conrado, E., Effect of the static pressure on the power dissipation of gearboxes. Lubr. Sci., 31(8), pp. 347-355, 2019.

[50] Sensinger, J. W., Unified approach to cycloid drive profile, stress, and efficiency optimization. J. Mech. Des. Trans. ASME, 132(2), pp. 245031-245035, 2010.

[51] Concli, F. \& Gorla, C., Oil squeezing power losses in gears: A CFD analysis. WIT Transactions on Engineering Sciences, 74, pp. 37-48, 2012.

[52] Concli, F., \& Gorla, C., Analysis of the oil squeezing power losses of a spur gear pair by mean of CFD simulations. ASME 2012 11th Biennial Conference on Engineering Systems Design and Analysis, ESDA 2012, 2, pp. 177-184, 2012.

[53] Concli, F. \& Gorla, C., A CFD analysis of the oil squeezing power losses of a gear pair. Int. J. Comput. Methods Exp. Meas., 2(2), pp. 157-167, 2014. https://doi.org/10.2495/ cmem-v2-n2-157-167

[54] Rundo, M., Models for flow rate simulation in gear pumps: A review. Energies, 10(9), 2017. https://doi.org/10.3390/en10091261

[55] Serov, A. F., Nazarov, A. D., Mamonov, V. N. \& Terekhov, V. I., Experimental investigation of energy dissipation in the multi-cylinder Couette-Taylor system with independently rotating cylinders. Appl. Energy, 251, 2019.

[56] Fu, X., Liu, G., Tong, R., Ma, S. \& Lim, T. C., A nonlinear six degrees of freedom dynamic model of planetary roller screw mechanism. Mech. Mach. Theory, 119, pp. 22-36, 2018. https://doi.org/10.1016/j.mechmachtheory.2017.08.014

[57] Burka, E. S. \& Ciania, W., An approximate method determining volumetric losses in radial clearance of a gear pump, 1987. 